\title{
Postburn Knee Flexions Contractures: Anatomy and Methods of Their Treatment
}

\author{
Viktor M Grishkevich ${ }^{1 *}$ and Vishnevsky AV $^{2}$ \\ ${ }^{1}$ Department of Reconstructive and Plastic Surgery, Russian Academy of Medical Sciences, Moscow, Russia \\ ${ }^{2}$ Institute of Surgery of the Russian Academy of Medical Sciences, Moscow, Russia
}

\begin{abstract}
Background: Postburn knee flexion contractures cause functional limitations of all lower extremity, not allowing the patient to walk normally, creating serious cosmetic defects, and, therefore, requiring surgical reconstruction. The anatomic features of knee flexion contractures and their treatment have been covered in literature far less than large joints of the upper extremities, and their treatment is still a challenge for many surgeons.
\end{abstract}

Methods: Anatomy of postburn knee flexion contractures in 58 patients was studied and contractures were surgically eliminated by using new approaches and techniques. Follow-up results were observed from 6 months to 12 years.

Results: Knee postburn flexion contractures were divided into three anatomic types: edge, medial, and total. Edge contractures were caused by scars located on the lateral or medial knee surface and were characterized by the presence of the fold along the popliteal fossa edge. The lateral sheet of the fold was scarred and $\mathrm{k}$ ulcerous scars should be excised. The study is the original research of the $1^{\text {st }}$ level of evidence.

Conclusion: Three anatomic types of knee scar flexion contractures were identified: edge, medial, and total. An anatomically justified technique for edge and medial contractures was trapeze-flap plasty. Total and most medial contractures were efficiently eliminated with scar excision and skin grafting; rarely was external distractor needed.

Keywords: Knee burns; Knee scar contracture; Knee contracture treatment; Trapeze-flap plasty

\section{Introduction}

Knee postburn scar flexion contractures, making up $22 \%$ of large joint contractures [1], affect the leg motion, impair the lower extremity function, present cosmetic defects, and requiring surgical treatment. The contracted scars undergo (during joint extension) severe tension, tearing, and often are converted to pathologic scars-rough, thick, solid, prone to keloid growth and ulceration. Review of literature shows that there is less research on knee scar flexion contractures, than on the large joints of upper extremities, when it comes to surgical treatment. There is no existing anatomical classification of flexion contractures that could serve as a guide, for reconstructive technique choice, which presents a clinical challenge [2]. Many surgical techniques have been described; however, an ideal method is yet to be found [3]. The most common treatment methods are based on the incisional contracture release and skin grafting or on the local triangular flap techniques [4]. Rarely, regional pedicled or free flaps and Ilizarov fixator are used. Most of these methods were tested in our institute; a high rate of complications and contracture recurrence induced us to search for a more efficient approach.

This paper presents the anatomical classification of knee postburn flexion contractures and specific techniques for treatment every type and results [5-16].

\section{Material and Methods}

Fifty-eight patients with postburn knee scar contractures were studied and operated on personally during past 16 years, from one to six years after burns; among them, 21 were male and 37 female; age ranged from 3 to 48 years, 18 were children. All patients sustained deep partial-and full-thickness burns from 9 to $28 \%($ mean $=19 \%)$ of the TBSA (total body surface area) resulting in knee flexion contracture formation. Anatomical features of knee scar contractures were studied prior to and during the operation, immediately after surgery and periodically from 6 months to 12 years after surgery. Research was done on the possibility of the maximum use of local and adjacent tissue in reconstruction, as well as research on flap and skin graft behavior after reconstruction. Results were considered good if there was complete contracture release (full knee joint extension of at least $180^{*}$ and flexion of $120^{*}$ ) and donor site morbidity was acceptable. Thirty-six patients studied earlier in whom incisional contracture release and triangular flaps (Y-V and Z-plasty and their modifications) were used were not included in this series.

\section{Results}

\section{Knee flexion contractures anatomy and terminology}

Specific anatomical features of knee flexion contractures were the result of burns located on the lateral joint surface (medial or lateral), or posterior (popliteal area), or all three surfaces (both lateral and popliteal) together. Corresponding with scar location, three anatomic contracture types were formed.

*Corresponding author: Viktor M Grishkevich, Department of Reconstructive and Plastic Surgery, Russian Academy of Medical Sciences, Moscow, Russia, E-mail: grishkevichmail@gmail.com

Received September 12, 2013; Accepted October 02, 2013; Published October 07, 2013

Citation: Grishkevich VM, Vishnevsky AV (2013) Postburn Knee Flexions Contractures: Anatomy and Methods of Their Treatment. Trop Med Surg 1: 147. doi:10.4172/2329-9088.1000147

Copyright: (c) 2013 Grishkevich VM, et al. This is an open-access article distributed under the terms of the Creative Commons Attribution License, which permits unrestricted use, distribution, and reproduction in any medium, provided the original author and source are credited. 
Citation: Grishkevich VM, Vishnevsky AV (2013) Postburn Knee Flexions Contractures: Anatomy and Methods of Their Treatment. Trop Med Surg 1: 147. doi:10.4172/2329-9088.1000147

\section{Edge knee flexion contracture anatomy (Figure 1)}

In the case of lateral joint surface injury (38 of 58 patients (65.6\%)): (a) the popliteal area (flexion surface) remained undamaged; (b) contracted scars formed a crescent fold along popliteal fossa edge; (c) the crest of the fold was the scar's edge; (d) the scars of the fold consisted of the two sheets: scar lateral (according to popliteal fossa), which the contracture caused, and healthy medial sheet, spreading on undamaged popliteal fossa. These anatomical features determined the name for this type, edge (Figure 1A). A fold's length and its protrusion differ from case to case, depending on the contracture severity. Contracture is caused only by the scar sheet in which there is a surface deficit in length, and spreads, subsiding, from the fold's crest to the joint rotation axis.
The form and size of the scar's surface deficiency (reason for contracture) must be determined since reconstruction's aim is to compensate for the deficiency with an adequate flap. The form and size of scar surface deficiency is estimated using the following steps: the scar sheet is separated from healthy skin with an incision along the fold's crest; with a Y-shaped perpendicular incision, the scar sheet is dissected from the fold's crest to the joint rotation axis level where incision is split under 45 degrees, forming a 90 degree angle. After joint extension, a trapezoid wound appeared, as a rule, reflecting the real scar surface deficiency (Figure 1B). The wound's form indicated that the flap should have a trapezoid form (Figure 1B). Both sheets have surface surplus in width.
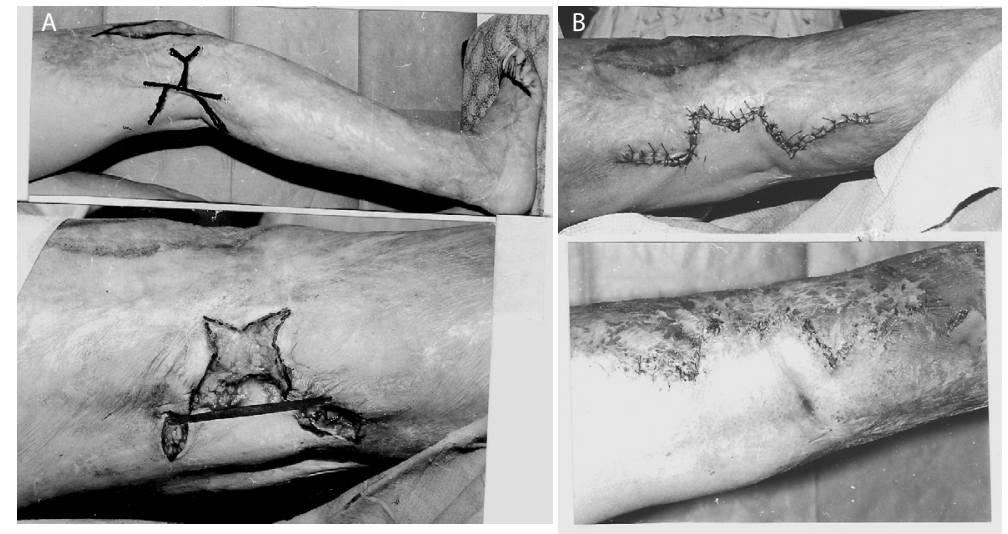

Figure 1: Postburn knee edge scar contracture: anatomy

a: fold along edge popliteal fossa; only lateral fold's sheet is scar, medial sheet and fossa is healthy skin; planning of operation: line for scar dissection by Y-incision up to joint rotation axis, line along fold's crest and flap's borders

b: trapezoid wound (scar surface deficiency) appeared (above white strip) after scar and fat layer incision and knee extension, flap mobilized.

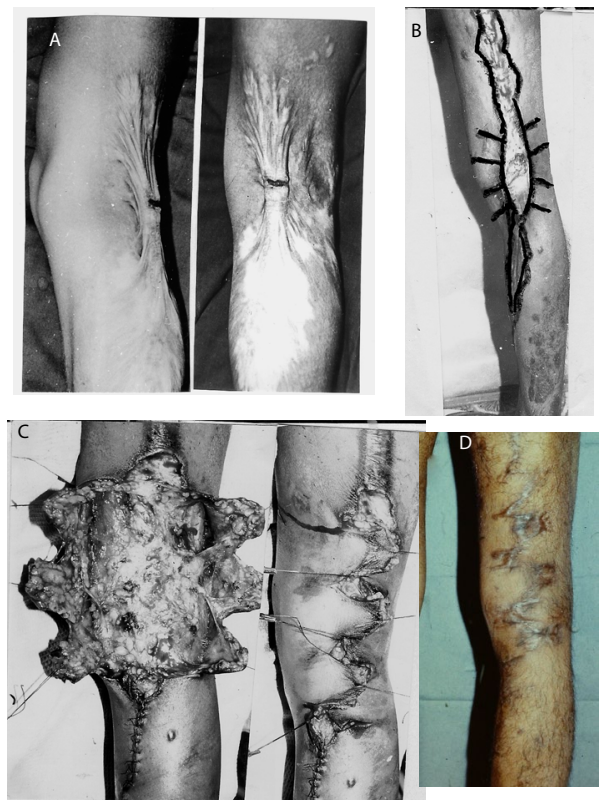

Figure 2: Knee medial scar contracture: anatomy and treatment with trapeze-flap plasty

a: contracted scars covered popliteal area and formed fold along medial popliteal line, both fold's sheet are scars; wound at fold's crest

b: (next case), left- planning of operation; right- 3 pairs of adipose-cutaneous trapezoid flaps mobilized, rough ulcerous scars excised

c: left - counter flap transposition; right- two years after operation: contracture eliminated in full

d: scar surface deficit compensated with trapezoid flap. 


\section{Anatomy of the knee flexion contractures after burns of popliteal area (Figure 2)}

Scars in popliteal area observed in 14 out of 58 patients (24.1\%) and: (a) formed a crescent fold located along the medial line of popliteal fossa; (b) both sheets of the fold were scarred and spread from the fold's crest to the popliteal fossa's edges (Figure 2A). These two anatomical features determined the name for this type, medial, which occurred in 5 cases. Both scar sheets of the fold have a surface deficiency in length (cause of a contracture) and surface surplus in width which allowed contracture treatment with local flaps. The fold can be small and short or may spread to the thigh and leg. The form and size of the scar sheet surface deficiency in length (the cause of the contracture) is estimated the following way: the fold sheets are divided with an incision along the fold's crest; contracture is released by a perpendicular Y-shaped incision from the fold crest to the popliteal fossa edges. After joint extension, as a rule, the trapezoid wound appeared in both scar sheets, which was maximal at the fold crest and spread, subsiding, to the popliteal fossa edges (Figure 2B). Besides, the fold's sheets have a surface surplus in width, which allow the contracture to be eliminated with local tissue (Figure 2C). Consequently, adequate contracture treatment of knee medial contracture can be performed by means of surface deficiency compensation with the trapezoid flaps.

In 9 patients, scars in popliteal area were pathological-rough, thick, red, keloid - and, therefore, found unfit for plasty (Figure 2). Scars in popliteal area undergo severe tension while walking; therefore, the scars tear first in the maximal tension zone (crest); after that, a small wound gradually converted to a chronic ulcer (Figure 2A, B); the normal scars became pathological which were inconvenient for the reconstruction use.

\section{Total knee joint contracture (Figure 3)}

After deep vast burns, scars tightly surrounded the knee, creating severe scar surface deficit without fold (6 patients, $10.3 \%$ of the total number). Reconstruction with a local flap was excluded. These anatomical criteria characterized a total. Due to severe tension while joint was extended, scars were converted to pathologic (solid, rough, thick), prone to necrosis and ulceration. Along with the scar contracture, deep burns could injure the articular structures (two of 6 patients), making the contracture more severe and complex for treatment.

\section{Reconstructive Techniques}

The anatomical features, specific for every contracture type, predetermined an adequate surgical technique choice.

\section{Reconstructive techniques for edge contracture elimination (38 patients)}

Depending on contracture severity, ulceration presence, and patient's age, several techniques were used.

\section{One-flap technique}

In the case of mild-to-moderate contracture, reconstruction was performed with one trapezoid flap. Planning consisted of several lines drawn: along the fold crest for separating scars from healthy skin, a Y-shaped perpendicular line for scars dissection. The following lines marked flap boundaries (Figure 1A). The first incision separated the scar sheet from the healthy skin; then, the scar sheet and subcutaneous fat layer were dissected with a Y-incision from the fold crest up to joint rotation axis. Due to a Y-shaped incision and after knee joint extension, the wound's edges diverge, the wound accepted, as a rule, trapezoid shape,which presents a real contracture cause, and wound's end, the $\mathrm{M}$-form (Figure 1B). According to the wound size and form, but nearly $30 \%$ wider, the adipose-cutaneous flap was mobilized in popliteal area up to the opposite popliteal fossa's edge, including the medial fold's sheet and all subcutaneous fat layer. The flap end was nearly $5 \mathrm{~cm}$ in width and included a part of the fold's crest; the flap's length equaled a distance among popliteal fossa' edges plus medial healthy sheet (8-10 $\mathrm{cm}$ ). The flap's end was incised nearly $1 \mathrm{~cm}$ in depth for connecting with the same form (M) of wound's edge. The flap was transposed on the wound with tension until the flap's end achieved a wound's end. Angles of the scar sheet were approached to flap's base and covered the small donor wounds aside the flap (one-flap technique; Figure 1C, upper).

\section{Three-flap technique (Figure 2)}

In case of more severe contracture, scar surface deficit and trapezoid wound, formed after scars dissection, were larger than in previous case (Figure 2A and 2B). Therefore, the donor wounds on both sides of the trapezoid flap were covered with adipose-scar trapezoid flaps, prepared from the scar sheet (Figure 2C and 2D).

\section{Multiple-flap plasty (Figure 3)}

Severe contracture and scar surface deficit that is caused by a long fold (Figures 3A-3C). The fold's sheets on all of the extent were converted to adipose-cutaneous and adipose-scar flaps. Counter flaps transposition allowed the contracture release without skin grafting (Figure 3D). Ulcerous scars, located at the fold crest, were excised first; then, the trapeze-flap plasty continued in the usual manner.

In children (under ten years), the contracted scars, causing a mild edge contracture, located on the lateral knee joint, hip, and leg surfaces, could be excised from the fossa's edge up to joint rotation axis (strip 5 to $7 \mathrm{~cm}$ in width), eliminating contracture and deformation (Figure $4 \mathrm{~A}$
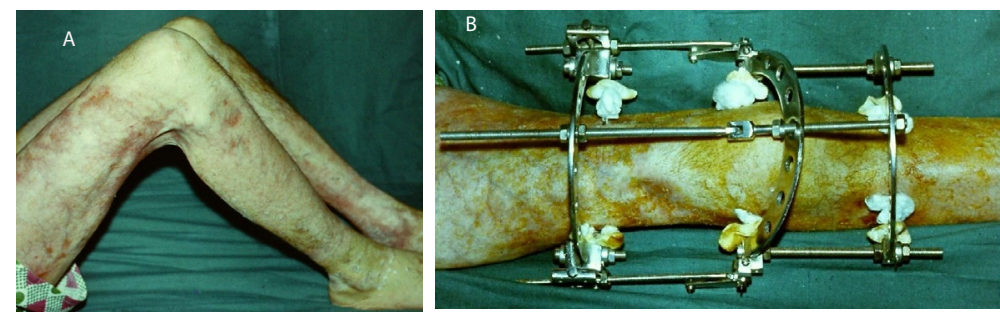

Figure 3: Total knee scar severe contracture: anatomy and treatment with wide scars excision, skin grafting and external distraction a: before operation: scars covered knee circularly without fold

b: knee distraction after wide scars excision and wound resurfacing with skin grafts. 

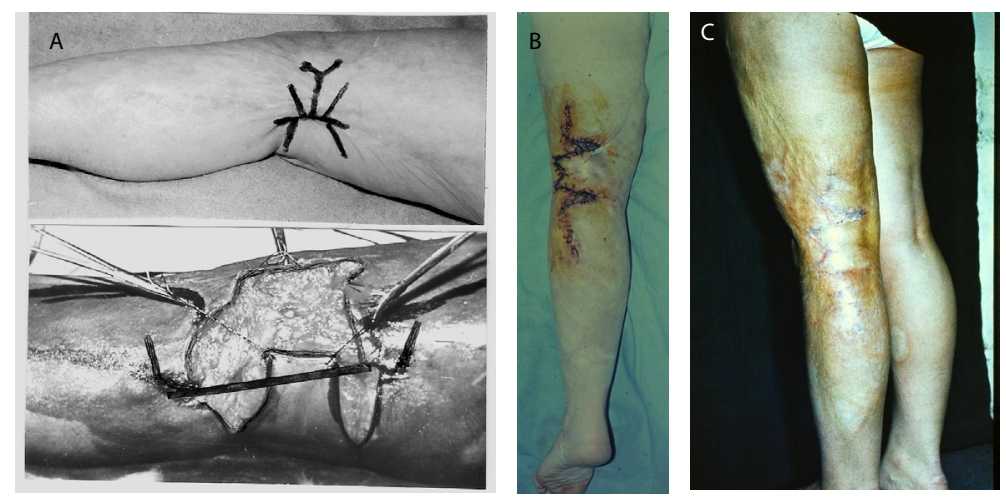

D
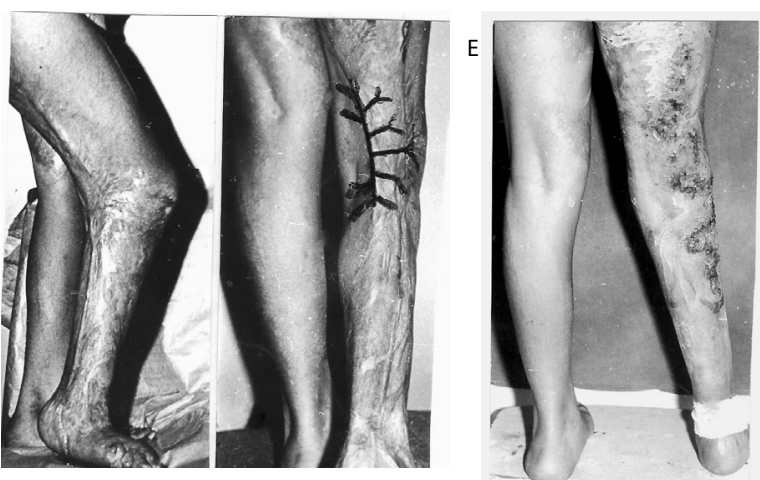

Figure 4: Knee edge contracture treatment with three trapezoid flaps. A, upper- fold along fossa's edge, planning of operation; $A$, medial- after scar dissection with Y-incision and knee extension, large trapezoid wound appeared (above black strip), trapezoid flap mobilized in popliteal region; two trapezoid adipose-scar flap marked a: lower- end of operation, contracture eliminated with 3 trapezoid flaps: main flap covered wound and scars' deficit compensated; flaps, prepared from scar sheet, covered small donor wounds aside main flap

b: follow-up result: contracture eliminated in full, flaps nearly noticeable, popliteal area restored; C (next case)- severe edge contracture elimination with several pairs of trapezoid flaps

c: , left - pre-operative view; C, right - planning of operation: long fold is converted into trapezoid figures (flaps) by radial line (incisions)

d: contracted scars dissected by Y-shaped incision, big trapezoid wound appeared (upper white strip), trapezoid flap mobilized from popliteal fassa

e: two weeks after operation: contracture fully released, all flaps alive.
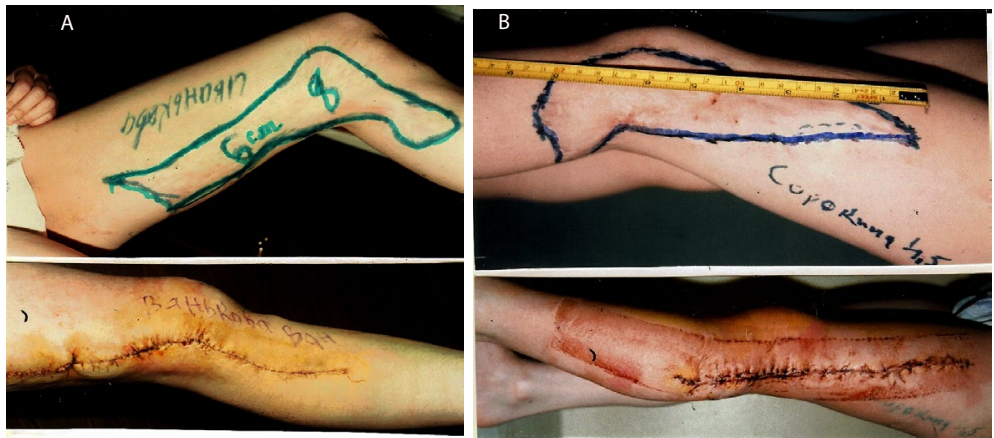

Figure 5: Knee edge contracture treatment in small children by scars excision and whole popliteal adipose-cutaneous layer transposition on the wound. a: Knee edge contracture treatment in small children by scars excision and whole popliteal

b: adipose-cutaneous layer transposition on the wound.

and $4 \mathrm{~B})$. Due to good tissue elasticity and displacement of the adiposecutaneous layer, the wounds were primarily closed without tissue mobilization.

\section{Knee medial contracture elimination techniques (14 patients)}

Two procedures were used. If scars of the fold were pliable and thin, the fold's sheets cars used for plasty ( 5 patients). The goal was to fully convert the fold's sheets in the flaps (Figure 5A and 5B). First, the ulcerous fold's crest was excised, and fold's sheets were divided along all fold's crest. As the fold has a crescent form, the Y-shaped incisions from the fold's crest to the popliteal fossa's edges converted the sheets in the flaps which, as a rule, accept trapezoid form. After knee extension, the wounds also accept the trapezoid form. The flap's end was nearly $5 \mathrm{~cm}$ in width and included part of the fold crest, the flap base corresponds to the popliteal fossa's edge. Scars and full subcutaneous fat layers are included in the mobilized flap, having steady blood supply Flaps were counter transposed with tension. Flap's ends were approached to the apposite flap's base (Figure 5C). 

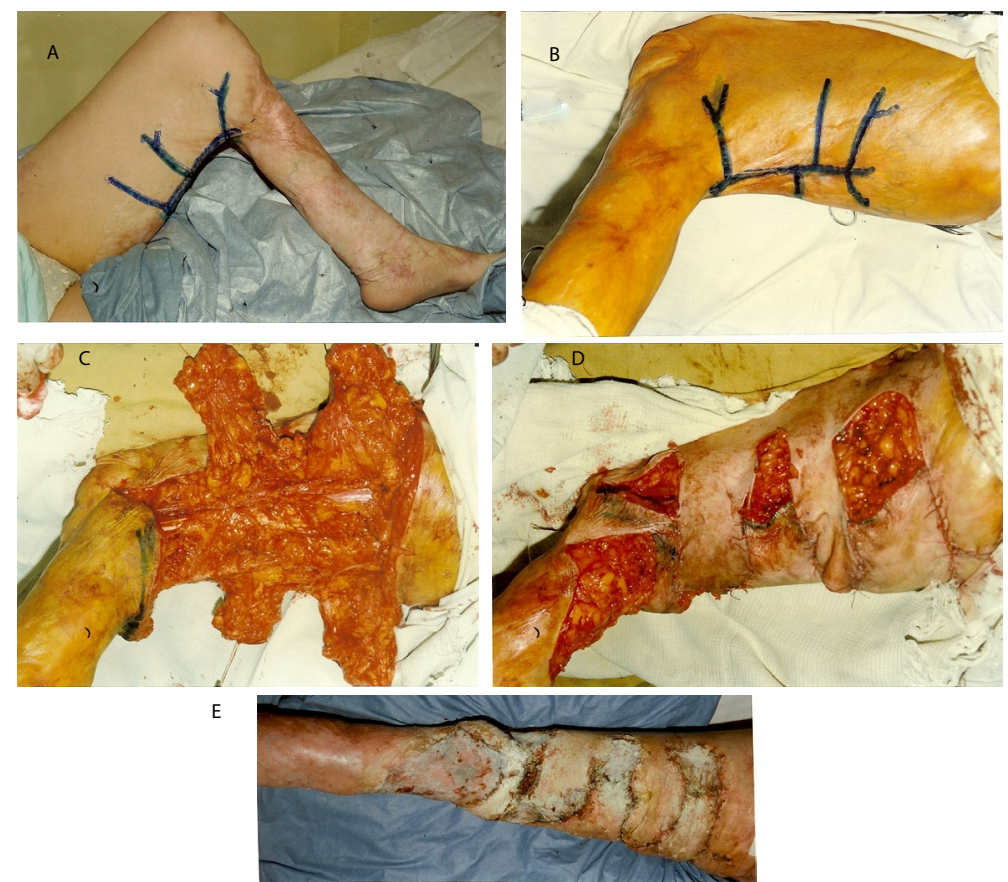

Figure 6: Knee severe medial contracture treatment with trapeze-flap plasty

a: before operation, planning

b: before operation, planning

c: adipose-scar flaps mobilized

d: counter transposed flap covered most flexion surface, residual wound will be grafted

e: 10 days after surgery: flaps and transplants alive, contracture released complete.
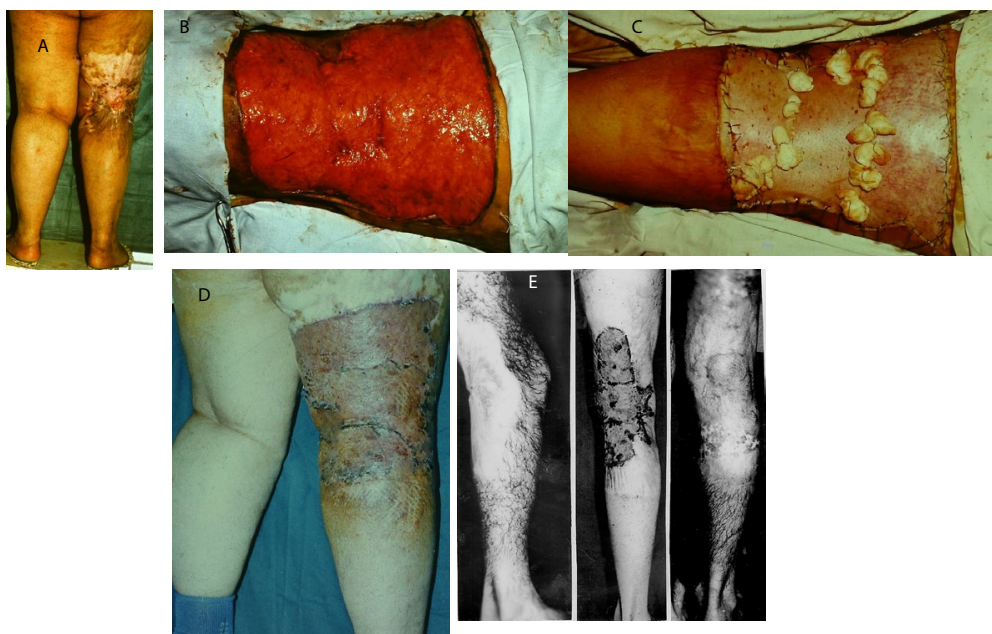

Figure 7: . Knee medial contracture treatment by wide pathological scars excision and skin grafting

a: prior to operation, rough ulcerous scars, covering popliteaal area

b: scars excised through intermediate layer, no bleeding, fat layer not injured

c: wound covered with split skin grafts

d: three weeks after operation: contracture released, transplants alive

e: (next case) - knee medial contracture, pathologic scars, ulcerous fold's crest, two years after scars' excision and skin grafting: contracture released in full, no shrinkage of skin grafts, no re-contracture.

Depending on contracture severity and fold length, one or several pairs of the flaps were elevated until contracture could be fully released and wound covered with flaps. In the case of severe contracture, the flaps covered the central knee flexion zone; residual wounds were skin grafted (Figure 6). The rate of lengthening always exceeded $100 \%$ (sum of all flaps in their middle width minus the length of the crest involved in plasty) [17-25].

Scars, covering popliteal area, in 9 cases (Figure 7A) were pathological (rough, thick, solid, and ulcerous) and impossible 
Citation: Grishkevich VM, Vishnevsky AV (2013) Postburn Knee Flexions Contractures: Anatomy and Methods of Their Treatment. Trop Med Surg 1: 147. doi:10.4172/2329-9088.1000147

Page 6 of 8

to convert in the flaps. Such matured scars were excised through intermediate layer, which was formed during scar maturation from solved scar's inner surface and has scanty amounts of vessels (Figure 7B). Only after scars' excision, the knee is extended with caution. For fatty layer tearing prevention, the surgeon lays its palm on the wound, creating pressure during knee extension. The split transplants placed on such wound's surface grow well; their shrinkage is minimal, what prevents a contracture recurrence (Figure 7C and 7D).

\section{Total knee contracture treatment}

The operation consisted of pathologic ulcerous scars excision in the popliteal area and lateral joint surfaces. Manual knee extension was combined with pressure on the wound by the surgeon's palm to prevent fat tissue tearing and solid structure exposure. In cases of severe total contractures, complicated by ulcers (Figure $8 \mathrm{~A}$ and $8 \mathrm{~B})$, pathologic scars were excised in one block with ulcers; the exposed vessels and nerves were covered with the local fat tissue transposition and the wound was covered with skin grafts (Figure $8 \mathrm{C})$. If necessary (two patients), external distractor was applied (Figure 8D).
After surgery, the usual gutter splint was applied for 3-5 weeks with 5-day antibiotic therapy.

\section{Results of Operations}

Knee flexion contractures were eliminated fully in all 58 patients. In 39 patients with edge contractures, the adipose-cutaneous trapezoid flaps and whole adipose-cutaneous layer (in children), rose from popliteal area, were alive and tolerated tension well (Figure 1 and 4). During long-term observation, the flaps did not shrink, but continued to grow, especially in pediatric patients, preventing the contracture recurrence, normalizing skin tension and contours of the popliteal fossa. In 2 cases, a marginal superficial necrosis in adipose-scar flaps occurred; wounds healed under dressings without consequences. Follow-up results were functionally excellent; donor site (popliteal fossa) preserved normal outlines without deformities with operation scars. In case of medial contractures, after trapeze-flap plasty (5 patients), no scar flap's loss was observed: good follow-up results were achieved (Figure 2). Skin grafts in 9 patients covered wounds without complication and were functioning well during all terms of observation, without signs of ulceration and re-contracture (Figure 7). Total contracture successfully
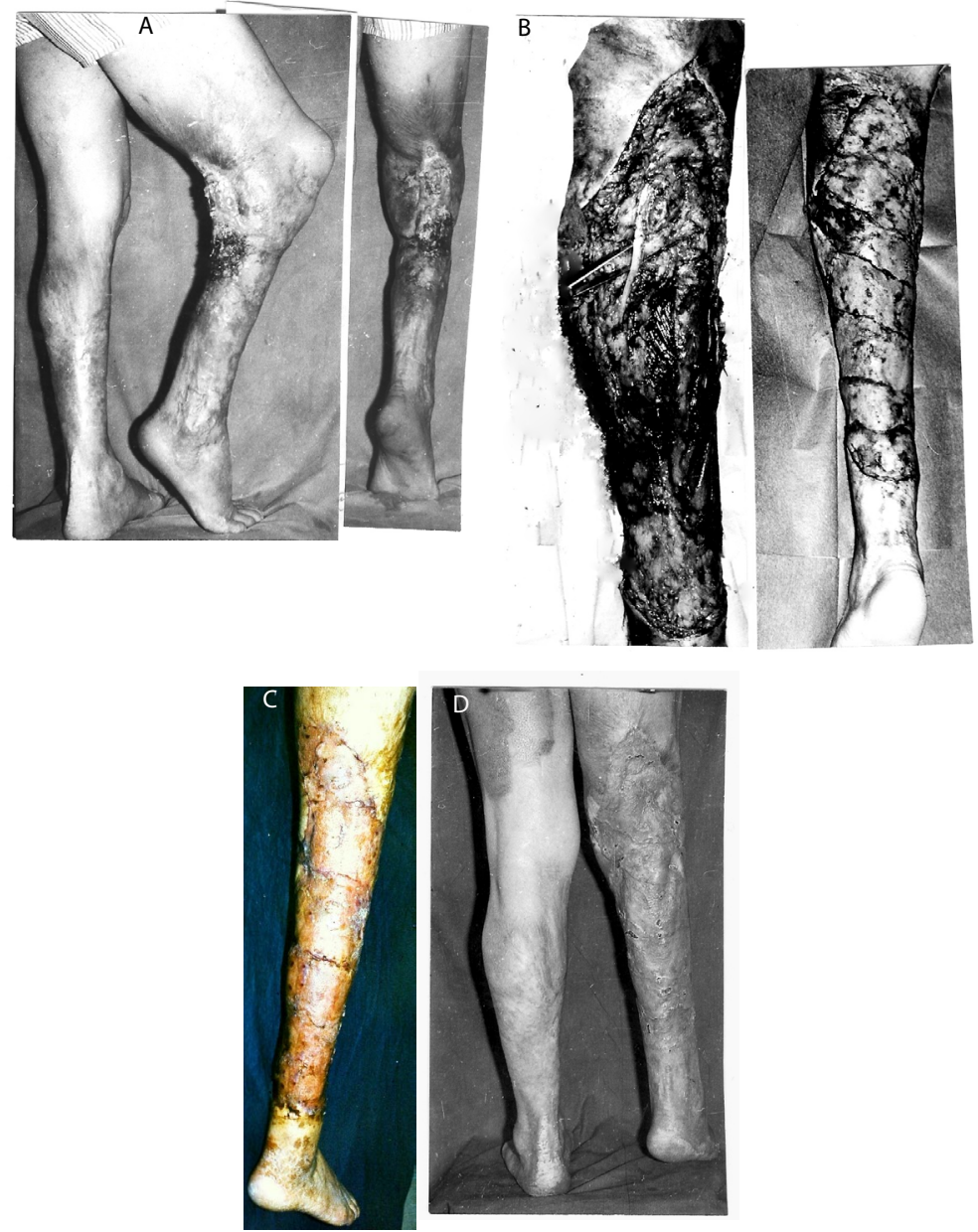

Figure 8: Severe total knee contracture treatment by wide ulcerous scars excision and skin grafting.

a: pre-operative view

b: scars excised through intermediate layer, no bleeding, fat layer not injured, exposed nerve covered with fat tissue; right- wound covered with whole split skin grafts c: wound covered with skin grafts

d: months after reconstruction: good functional and cosmetic result. 
eliminated in all 4 patients treated only by wide scar excision and skin grafting; in 2 patients, along with the scars excision and skin grafting, the external distraction was used with good outcomes (Figure 3). The skin transplants, covering large wound, converted to well-functioned skin (Figure 8); therefore, wide scar excision and skin grafting significantly improved all extremity appearance.

\section{Discussion}

Knee scar flexion contractures need to be reconstructed as early as possible to improve the loss of a patient's activity and prevent kyphosis development. The goal is to return the patient to society in as normal a function and appearance as possible [25-34]. Literature data presents the following known classifications and techniques proposed for knee contracture treatment.

\section{Classification and terminology}

Literature analysis shows that the knee flexion contracture anatomy and treatment have been researched less than other big joints. There no anatomical classification; nest names are used: web, straight linear, wide, linear, wide and quadratic, wide linear; long. Ogawa and Pribaz [33] classified knee contracture into 5 forms: linear (anterior, posterior, tibial or peroneal); broadband (the same subdivision as previous form); broadband contractures extended to neighboring surfaces; broadband contractures of entire circumferences; others [1-5,16-18,30-33].

Listed classifications (lineal, wide, broadband, long, web) determine a scar's form but not disclose complete anatomical contracture form and its cause; they do not serve as a guide for the adequate technique and flap choice and not allow the results comparison of their application.

According to our data, contracture formation is determined by scar location on the joint: lateral surface, popliteal surface or circumference. Laterally located scars form a fold along the popliteal fossa edge, allowing the contracture treatment with local tissue. Contracture is caused only by a lateral scar sheet due to scar surface deficiency in length which has a trapezoid form. The crest of the fold is the scar's edge. Therefore, such contracture is named as edge type. Scars in popliteal area form the fold (contracture cause) along with medial popliteal line; both fold's sheet are scars; therefore, the contracture named as medial. Both sheets of the fold have a trapeze-shaped surface deficit in length (contracture cause) and surface surplus in width. Surface surplus in both fold's sheets allows contracture elimination with local tissue, compensating scar surface deficiency. Scars, tightly surrounding joint without fold, what excludes local-flap plasty, named as total.

Incisional contracture release and wound resurfacing with skin grafts [6]; incision with progressive stretch load [7], quadra $Z$ technique [3]. MacCauley and Asuku [6] write that incisional or excisional release and skin grafting is frequently the first line of therapy with excellent long-term results.

Our experience showed that after scar incision, during knee extension, the scar edges diverge, involving the fat tissue, which is torn, baring solid popliteal structures and creating a soft tissue defect. The scars aside the wound continue to stay in contracted condition, creating residual contracture. The skin grafts, placed on such wound, shrink and contracture recurs ( 8 cases). Therefore, we no longer apply the incisional release in case of medial and total contractures caused by scars located on the joint's flexion surface. Pathological scars excision on all popliteal area yields the positive outcome. In case of edge contracture, the fatty layer is dissected up to deep fascia; appeared soft tissue defect (scar surface deficit) is resurfaced with popliteal adipose-cutaneous flap.

\section{Reconstruction with local flaps}

Z-plasty and its modifications [8,9]. Dougherty et al. [4] write that for medially or laterally located (edge contracture) skin flaps are preferable to skin grafts; Z-plasties or V-Y advancement flaps may be sufficient in most cases. Buis et al. [10] reported that a conventional Z-plasty on postburn scar tissue frequently leads to varying degrees of necrosis of the tips of the transposed flaps. Proposed interpositional skin-flap procedure [11] is Z-plasty modification.

$\mathrm{V}-\mathrm{Y}$ plasty and its variations [12-14]; double-opposing Z- and $\mathrm{V}-(\mathrm{K}-\mathrm{M}-\mathrm{N})$ plasty [15] and rectangular advancement flap in the treatment of wide linear contractures [16];

- Seven flap plasty [17]; method consists of two half Z-plasties and one W-M plasty;

-Circumferential incision technique which is similar to the double opposing V-Y plasty [18].

Efficacy of V-Y procedure depends on depth of the flap's advancement only which is restricted, as the flaps are not mobilized [19]. Gumus [14] concluded: V-Y technique use undermined flaps, which can not close the defect completely.

Other flaps and techniques are recommended for concrete knee contracture or all scar contractures, including the knee: -Z-lengthening of tendons and gastrocnemius muscle flap [20]; distally-based fasciocutaneous thigh flap [21,22]; medial sural perforator plus island flap for the reconstruction of postburn knee [23]; proximally-based sural flap [24,25]; posterior calf fascial flap [26]; anterolateral thigh free flap [21].

Ilizarov technique [27], after which a high rate of contracture recurrence have been noticed [28]; combined Ilizarov technique and free flap for severe recurrent flexion contracture release [29]. Efficacy of proposed techniques and indications of their use impossible to estimate and determine as a contracture type stayed unknown. Dougherty et al. [4] discern two forms: (a) medially or laterally with unburned skin posteriorly (popliteal fossa) which is successfully treated with local triangular or transposition flaps (the first choice) and (b) contracture of the entire popliteal area which is treated with incisional release and skin grafting.

\section{References}

1. Schneider JC, Holavanahalli R, Helm P, Goldstein R, Kowalske K (2006) Contractures in burn injury: defining the problem. J Burn Care Res 27: 508-514.

2. Hudson DA, Renshaw A (2006) An algorithm for the release of burn contractures of the extremities. Burns 32: 663-668.

3. Sen C, Karacalar A, Agir H, Dinar S, Isil E, et al. (2007) A simple and effective procedure for treating burn contractures: releasing incision and quadra $Z$ technique. Burns 33: 241-245.

4. Dougherty WR, Coleman 111 JJ, Sood R (2006) Reconstruction of burn of the lower extremity. In: Sood R, editor Achauer and Sood's burn surgery. Reconstruction and rehabilitation. Philadelphia, PA: W.B.Saunders; p. 326-37.

5. Mani MM, Chhatre M (1992) Reconstruction of the burned lower extremity. Clin Plast Surg 19: 693-703.

6. McCauley RL, Asuku ME (2005) Reconstruction of burn deformities of the lower extremity. In: McCauley RL, editor. Functional and aesthetic reconstruction of the burned patients. Boca Raton: Taylor and Franciss Ch.57; p. 521-47.

7. Al-shaham AA (2008) Progressive stretch-load is a principle step in the surgica treatment of burned knee contracture. Internet J of Plastic Surgery 2: 3 .

8. Gokrem S, Baser NT, Akbuga UB, Yalaz B, Aslan G (2008) Nine-flap z-plasty: a new modification of five-flap z-plasty. Burns 34: 292-293. 
Citation: Grishkevich VM, Vishnevsky AV (2013) Postburn Knee Flexions Contractures: Anatomy and Methods of Their Treatment. Trop Med Surg 1: 147. doi:10.4172/2329-9088.1000147

9. Chan RK, Donelan MR. Use of Z-plasty in burn reconstruction. In: Hyakusoku $\mathrm{H}$, Orgill DP, Teot L. editors. Color atlas of burn reconstructive surgery. 201? Ch. $21 ;$ p. $172-7$.

10. Buis J, Soupre V, Picard A, Le Louarn C, Servant JM, et al. (2009) [Z-plasty low tension]. Ann Chir Plast Esthet 54: 370-373.

11. Huang $T$ (2002) Management of contractural deformities involving the shoulder (axilla), elbow, hip, and knee joints in burned patients In: Herndon D, editor. Total burn care. Philadelphia, PA; Ch. 52, p. 695-706

12. Askar I (2003) Double reverse V-Y-plasty in postburn scar contractures: a new modification of $\mathrm{V}$-Y-plasty. Burns 29: 721-725.

13. Daya M (2008) Clinical experience and analysis of length gain with the use of seven-flap plasty in burn contractures. Burns 34: 1022-1026.

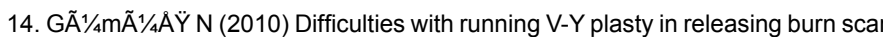
contracture. Ulus Travma Acil Cerrahi Derg 16: 407-412.

15. Emsen IM (2010)A new method in the treatment of postburn and post-traumatic scar contractures: Double-opposing Z- and V- (K-M-N) plasty. Can J Plast Surg 18: e20-26.

16. Ertå̊̈ N, Borman $H$ (2011) Double opposing rectangular advancement flap is an alternative technique in the treatment of wide linear postburn scar contractures. Burns 37: 1449-1457.

17. Suliman MT (2004) Experience with the seven flap-plasty for the release of burns contractures. Burns 30: 374-379.

18. Ezoe K, Yotsuyanagi T, Saito T, Ikeda K, Yamauchi M, et al. (2008) A circumferential incision technique to release wide scar contracture. J Plast Reconstr Aesthet Surg 61: 1059-1064.

19. van Niekerk WJ, Taggart I (2008) The size of the Y: the multiple Y-V plasty revisited. Burns 34: 257-261.

20. Chowdri NA, Darzi MA (1998) Z-lengthening and gastrocnemius muscle flap in the management of severe postburn flexion contractures of the knee. J Trauma 45: 127-132

21. Yildirim S, Avci G, Akan M, Misirlioğlu A, Aköz T (2003) Anterolateral thigh flap in the treatment of postburn flexion contractures of the knee. Plast Reconstr Surg 111: 1630-1637.

22. Uygur F, Duman H, Ulkür E, Celiköz B (2008) Are reverse flow fasciocutaneous flaps an appropriate option for the reconstruction of severe postburn lower extremity contractures? Ann Plast Surg 61: 319-324.
23. Kim KS, Kim ES, Hwang JH, Lee SY (2012) Medial sural perforator plus island flap: a modification of the medial sural perforator island flap for the reconstruction of postburn knee flexion contractures using burned calf skin. $J$ Plast Reconstr Aesthet Surg 65: 804-809.

24. Cheon SJ, Kim IB, Park WR, Kim HT (2008) The proximally-based sural artery flap for coverage of soft tissue defects around the knee and on the proximal third and middle third of the lower leg: 10 patients followed for 1-2.5 years. Acta Orthop 79: 370-375

25. Suri MP, Friji MT, Ahmad QG, Yadav PS (2010) Utility of proximally based sura artery flap for lower thigh and knee defects. Ann Plast Surg 64: 462-465.

26. Prakash V, Mishra A (2003) Use of posterior calf fascial flap: a new concept for the management of knee contracture with unstable scar. Plast Reconstr Surg 111: 505 .

27. Ullmann $Y$, Fodor L, Soudry M, Lerner A (2007) The llizarov technique in joint contractures and dislocations. Acta Orthop Belg 73: 77-82.

28. Huang SC (1996) Soft tissue contractures of the knee or ankle treated by the llizarov technique. High recurrence rate in 26 patients followed for 3-6 years Acta Orthop Scand 67: 443-449.

29. Bar-Meir E, Yaffe B, Winkler E, Sher N, Berenstein M, et al. (2006) Combined Iliazarov and free flap for severe recurrent flexion-contracture release. J Burn Care Res 27: 529-534

30. Cooper MA (1990) The multiple Y-V plasty in linear burn scar contracture release. Br J Plast Surg 43: 145-149.

31. Suzuki S, Um SC, Kim BM, Shin-ya K, Kawai K, et al. (1998) Versatility of modified planimetric Z-plasties in the treatment of scar with contracture. $\mathrm{Br} J$ Plast Surg 51: 363-369

32. Ertaş NM, Küçükçelebi A, Bozdoğan N, Celebioğlu S (2004) The use of subcutaneous pedicle multiple rhomboid flaps in the treatment of long postburn scar contractures. Burns 30: 594-599.

33. Ogawa R, Pribaz JJ (2010) Diagnosis, assessment, and classification of scar contractures. In: Hyakusoku H, Orgill DP, Teot L;Prribaz JJ,Ogawa R. Color atlas of burn reconstructive surgery. Springer; p. 44-60.

34. Grishkevich V (1991) The basic types of scar contractures after burns and methods of eliminating them with trapezeplasty flaps. Plast Reconstr Surg 88 1044-1054. 